\title{
Pueblos indígenas, saberes y descolonización: procesos interculturales en América Latina
}

\author{
Blanca S. Fernández \\ Instituto de Investigaciones Gino Germani - IIGG / FSOC, Universidad de Buenos \\ Aires. \\ Email: blancasoledadfernandez@gmail.com
}

\author{
Bastien Sepúlveda \\ Centro Interdisciplinario de Estudios Interculturales e Indígenas - ICIIS, Pontificia \\ Universidad Católica de Chile. \\ Email: bastien_sepulveda@yahoo.fr
}

Participar de la producción y de la difusión del conocimiento ha sido y es el propósito del programa educacional impulsado, en distintos niveles y a diferentes escalas, por muchos pueblos indígenas en América Latina. Desde la implementación de una educación intercultural bilingüe hasta la creación de universidades indígenas, numerosos y variados han sido los caminos explorados hasta hoy. Todos, sin embargo, parecen apuntar a la reapropiación de prerrogativas usurpadas en el transcurso de una historia marcada por el sello del colonialismo. Lo medular de estas demandas radica en una crítica ontológica a lo que el pensamiento crítico latinoamericano ha calificado como "colonialidad del saber".

¿Qué entendemos por “colonialidad del saber”? Es el resultado de un proceso que consiste, primero, en relegar el conocimiento producido por los grupos colonizados / dominados / minorizados en la periferia de la formación intelectual y, segundo, en imponerles otra forma de interpretar, entender y hacer el mundo. Así, vemos cómo la violencia que ejerció un modo particular y etnocéntrico de construir el conocimiento ha sido fuertemente cuestionada estos últimos decenios por una nueva generación de intelectuales indígenas, estrechamente vinculados al campo académico formal. Junto con reivindicar filiaciones y epistemes alternativas, estos intelectuales abogan por una descolonización del saber y una apertura de las estructuras donde éste se edifica.

En este sentido, resulta particularmente interesante entender el rol de la educación, considerada más como un medio para poder "infiltrar" la sociedad dominante y aprender a conocer sus dispositivos que como una instancia de aculturación. La educación fue, de hecho, uno de los terrenos 
de lucha arduamente practicado por los pueblos indígenas que tempranamente vieron en la instrucción una herramienta necesaria para defenderse de los abusos cometidos en su contra. Notamos de esta manera cómo, con el pasar de los años, las reivindicaciones indígenas por educación no han decrecido, intensificándose y extendiéndose incluso al ámbito educacional superior, donde ya se han formado varias generaciones de intelectuales indígenas.

En tanto lugar emblemático y formalmente establecido de producción y difusión de saberes, la universidad se halla inevitablemente en el centro del debate. Pero, ¿hasta qué punto puede efectivamente la universidad abrirse al proceso de descolonización pensado y reivindicado por los movimientos indígenas? ¿Constituye un espacio realmente legítimo y apropiado para la materialización de tal proyecto? ¿En qué medida podría contribuir a desverticalizar las relaciones de poder que estructuran el orden jerárquico establecido? Cabe señalar al respecto que, al margen del campo académico formal, se habla también de la posibilidad de crear instituciones universitarias propias, lo cual tensiona inevitablemente las formas dominantes de producir el conocimiento, reinventándolas. Estos espacios, pensados y construidos en conflicto con la institucionalidad estatal, luchan para ganar y sostener cierta autonomía organizativa.

En Chile, por ejemplo, esta idea viene atravesando ya varias décadas de lucha, desde la propuesta hecha por la Corporación Araucana en los años 1940 de crear un Instituto de Educación Indígena, hasta las demandas contemporáneas por la formación de una Universidad Mapuche. Otro ejemplo es el del Ecuador, donde se ha impulsado el Instituto Científico de Culturas Indígenas (ICCI) en 1986, ydesde 1995 la Universidad Intercultural de los Pueblos Indígenas AmawtayWasi. Lamentablemente, esta experiencia alternativa y autónoma que tenía reconocimiento oficial perdió su acreditación en 2013, bajo el argumento de no ajustarse a los “estándares de calidad” establecidos por el gobierno vigente. Así también, en México, las universidades interculturales indígenas ya se han hecho realidad, siendo no obstante el blanco de críticas respecto de la forma en que plantean en su diseño la construcción del proceso intercultural.

Como podemos observar, la interculturalidad ha sido, de manera general, el lema bajo el cual se ha pretendido refundar muchos programas educacionales en América Latina. De hecho, aunque en el limitado marco del multiculturalismo neoliberal, la mayoría de los países de la región otorgó rango constitucional al derecho a la educación intercultural. Existen experiencias múltiples y diversas que, con mayor o menor éxito, apuntan a lo que podríamos llamar una “interculturalización” de los currículos. La revitalización de las lenguas indígenas suele ocupar un rol central en estos procesos, hablándose de “educación intercultural bilingüe” (EIB). Es fundamental insistir en que, en el contexto de sociedades cuyas lenguas fueron subalternizadas, dicha revitalización condiciona las posibilidades efectivas de reconocimiento de epistemes propios y alternativos. Así, en América Latina, notamos cómo la minorización de las lenguas indígenas ha significa- 
do el silenciamiento de una gran diversidad de concepciones del mundo, de modos de pensamiento y, por consiguiente, de formas singulares de construcción de saberes.

No parece que la investigación en contextos indígenas pueda / deba eludir esta dimensión. Sin embargo, es importante tener presente el riesgo de esencialización y de repliegue epistémico atingente al proceso de construcción de una vía alternativa o proyecto educativo autónomo. En definitiva, la apuesta parece residir más bien en una voluntad colectiva por establecer un diálogo horizontal, en el reconocimiento y la valorización de una pluralidad de sistemas de saberes que problematice las condiciones asimétricas en que pueda producirse dicho diálogo. Estas, nos parece, constituyen condiciones sine qua non para la implementación de una "verdadera” interculturalidad.

Los artículos que componen la sección Lente de aproximación de este número monográfico de Polis encaran esta interesante pero intricada problemática. Parte de ellos fue presentada originalmente en el simposio "Pueblos indígenas, saberes y descolonización. Propuestas y perspectivas desde América Latina”, organizado en el marco del III Congreso Internacional de Ciencias, Tecnologías y Culturas, en la Universidad de Santiago de Chile, del 7 al 10 de enero de 2013. En la continuidad de los debates que animaron esta actividad, el conjunto de los trabajos incluidos en este dossier muestran que los desafíos planteados por la implementación de políticas educativas interculturales son tan numerosos como diversos. En este sentido, el dossier ofrece un panorama relativamente completo de las apuestas ligadas a la descolonización de los saberes y problematiza la asimetría que, en términos de relaciones de poder y dominación, atraviesa a los procesos educativos en contextos indígenas.

José Ancan recuerda en su artículo que esta asimetría es tan antigua como la llegada e implantación de la escuela en territorios indígenas. Basándose en la experiencia mapuche de comienzo del siglo XX en Chile, entrega un análisis fino de los dispositivos de poder que históricamente contribuyeron a estructurar las relaciones interétnicas y relegar los conocimientos indígenas a la periferia del saber institucionalizado en América Latina. Se imbuye así en las modalidades de despliegue del poder colonial, pero también en el rol de la instrucción o educación formal, así como en las estrategias y mecanismos usados por los líderes de la época, cuyas actuaciones prefiguraron las posturas de futuras generaciones de intelectuales mapuches. Las demandas indígenas por una educación intercultural -eventualmente bilingüe-, aunque muy disimuladamente, ya se venían perfilando en ese entonces; las formas en que el poder colonial las torciera y manoseara también.

Adentrándose en la brecha abierta por el trabajo de Ancan, gran parte de los artículos incluidos en este dossier se enfocan específicamente en las modalidades contemporáneas, tanto teóricas como prácticas, de la llamada “interculturalización” de los currículos. Tres de ellos atienden el 
caso de Brasil, donde el principio de interculturalidad ha sido oficializado en 2008 para la enseñanza básica y secundaria. Luana Barth Gomes, en particular, se focaliza en las repercusiones de la integración de saberes indígenas en una escuela situada en Porto Alegre, en contexto urbano, a la que asisten estudiantes de origen kaingang. La autora analiza esta experiencia educativa de enseñanza-aprendizaje, y observa las especificidades de una escuela que se constituye en un "espacio diferencial” de relación intercultural entre estudiantes indígenas y no indígenas.

Por su parte, Patricia Fortes y Rosália Silva se interesan en la forma en que la integración de profesores indígenas en escuelas municipales del Estado de Pernambuco permite generar espacios de empoderamiento y, a su vez, reafirmar la identidad colectiva de los pankará. Junto con destacar el proceso de "recuperación" de la educación, indagan tanto en los cambios político-pedagógicos que se producen a partir de las movilizaciones indígenas, como en los márgenes de autonomía que se generan para la comunidad educativa. En una línea argumentativa muy cercana, Chicoepab Suruí et alia analizan las medidas tomadas y/o demandadas por el pueblo paitersuruí en materia educativa en los Estados de Rondônia y Mato Grosso. Como lo demuestran, dichas medidas están plenamente incorporadas al proyecto territorial y autonómico de los paitersuruí, del cual constituyen incluso un componente indisociable. Se reafirma de esta manera la relevancia y centralidad del proyecto educativo indígena, el cual está intrínsecamente vinculado a las demandas por autonomía y territorio.

Sin agotar el abanico temático ligado a los procesos de “interculturalización”, las situaciones investigadas desde Brasil en estos tres artículos develan aspectos fundamentales identificados también en otros contextos nacionales. Desde Colombia, por ejemplo, Víctor Molina y José Tabares analizan el modelo de "educación propia” diseñado por las comunidades nasa de la montañosa región del Cauca. A través de un trabajo etnográfico en el resguardo indígena de San Lorenzo de Caldono, observan las tensiones que produce la convivencia de tres formas de educación -la propia, la oficial y la bilingüe intercultural-, compartiendo interrogantes acerca de la interculturalización como proceso democratizador. Por su parte, Pedro Fuenzalida, al interesarse en la integración de autoridades tradicionales en los programas de escuelas ubicadas en comunidades mapuchewilliches del sur de Chile, problematiza el riesgo de esencialización de los saberes indígenas. Avanza de esta forma en los debates acerca de la interculturalidad analizando los sentidos de la EIB y su implementación, considerando para ello las tensiones identitarias que estas experiencias producen en lo que refiere a la definición del curriculum.

Desde México, y en una perspectiva muy similar, Arturo Ruiz y Elena Quiroz destacan los pasos realizados en el marco de las Secundarias Comunitarias en el Estado de Oaxaca, sin dejar de cuestionar el sentido y la eficacia de un modelo educativo intercultural exclusivamente centrado en los saberes indígenas. Así, comparten una evaluación de las potencialidades y de los límites de esta experiencia local, desde la voz de sus protago- 
nistas. El nivel superior no escapa a estas críticas, como lo demuestra el trabajo de Paola Vargas quien analiza detalladamente la experiencia de la Universidad Intercultural de los Pueblos Indígenas Amawtay Wasi en el Ecuador. Junto con caracterizar los diferentes derroteros del proyecto educativo del movimiento indígena en su relación con el Estado, la autora pone en cuestión los contenidos prácticos de la noción de interculturalidad y de la propuesta de EIB en educación superior, así como las dificultades para consolidar prácticas interculturales en las instituciones estatales e indígenas.

$\mathrm{Al}$ atender distintos contextos nacionales y niveles educativos, los artículos aquí reunidos presentan un abanico amplio de situaciones que abren perspectivas comparativas y críticas particularmente interesantes en el campo de la interculturalidad en América Latina. Develan, además, el carácter dinámico y fuertemente integrado de la interculturalidad que se presenta más como un proceso continuo en constante negociación y reelaboración, que como un mero principio que pueda ser oficial y definitivamente establecido. Existen sin embargo principios que guían, pautan y de alguna forma moldean invariablemente dicho proceso, como ocurre por ejemplo con la revitalización de las lenguas indígenas. Como ya lo señalamos más arriba, la revitalización lingüística condiciona las posibilidades efectivas de reconocimiento de epistemes propios y alternativos. No es casual entonces que la lengua constituya un elemento esencial de las reivindicaciones indígenas y de los procesos de "interculturalización”, como lo atestiguan varios de los artículos de esta sección monográfica.

Considerando que cualquier conocimiento se elabora en un contexto social, cultural y político determinado, el origen y el rol o funciones de quien o quienes enuncia(n) dicho conocimiento no es neutral. ¿¿Quién habla y desde dónde? La lengua, en tanto elemento constitutivo de la cultura, es indudablemente una herramienta de comunicación pero también un arma para la lucha política. Esto es precisamente lo que plantea Gabriel Pozo quien, en su artículo, focaliza su atención en el rol del mapudungun en el proceso de revitalización cultural mapuche en Chile. Al abrir la discusión sobre el uso y la integración de las lenguas indígenas en el trabajo de investigación, el autor plantea una necesaria reflexión acerca del compromiso ético y profesional de la comunidad científica para con los pueblos indígenas.

No está de más insistir en que el reconocimiento y la valoración de las lenguas indígenas permitiría develar otras ontologías, es decir otras formas de ver y hacer el mundo, alternativas a lo que Gonzalo Zubia identifica en su artículo como la "discursividad hegemónica" de la modernidad. Como bien menciona el autor, el paradigma de la modernidad -y la discursividad que le es asociada- se caracteriza -entre otras- por su propensión a hacer desaparecer y/o invisibilizar la existencia de otras discursividades y las diferencias culturales que de ahí derivan. Al contraponer la concepción moderna del territorio, ilustrada en este caso por la explotación de litio en las Salinas Grandes, con la de las comunidades kollas 
en la provincia argentina de Jujuy, evidencia cómo diferentes marcos de análisis o niveles de lectura dan sentidos diferenciados a los lugares y los territorios.

Llegamos nuevamente de esta manera al rol de la modernidad / colonialidad no sólo en desconocer o ignorar una infinidad de sentidos diferenciados, sino también en deslegitimarlos e invisibilizarlos. Afrontando este contexto, el artículo de Sergio Caba y Gonzalo García ahonda en el potencial descolonizador y la capacidad de superar el eurocentrismo del pensamiento social latinoamericano, invitando también indirectamente a reflexionar sobre el rol y la responsabilidad de la comunidad científica para con la situación colonial y los procesos de descolonización en América Latina. Lo que final y abiertamente plantean los autores en este trabajo es la existencia de una multitud de obstáculos de orden epistémico en la tarea propuesta de descolonización.

Lo complejo de dicha tarea radica indudablemente en la multidimensionalidad del fenómeno colonial. Pues, el colonialismo no se despliega únicamente desde lo racial o lo étnico, sino que incluye también otras dimensiones, imbricadas entre sí. Una de ellas es la de género, como lo demuestra Antonieta Vera quien discute, en su artículo, la posible identificación de un “feminismo mapuche”. Al enmarcar su reflexión en los debates desarrollados en otros contextos en torno a los "feminismos de color", la autora desenmascara una categoría de análisis que permite cuestionar la colonialidad tanto en su dimensión racial como de género, discutiendo así las oposiciones, jerarquías y formas entrelazadas de dominación derivadas de un sistema impuesto y/o reproducido desde una normatividad blanca heterosexual tanto masculina como femenina. De tal suerte que el texto atiende, problematiza y profundiza una propuesta anticolonial y de desmantelamiento del colonialismo que afecta doblemente a las mujeres indígenas en América Latina.

¿Qué hacer y cómo descolonizar en este contexto? Si bien ya señalamos la existencia de obstáculos teórico-epistémicos que de alguna manera entorpecen los procesos de descolonización, la resistencia empírica al colonialismo desde la realidad indígena proporciona interesantes experiencias al respecto. Esta resistencia, más allá de la apropiación e incorporación estratégica de herramientas modernas, como lo discuten entre otros Suruí et alia para el caso de los paitersuruí, pasa por un proceso de recuperación simbólica del control de las representaciones. El artículo de Karliane Nunez et alia atiende precisamente esta problemática a través de una interesante experiencia de trabajo en el campo de la producción cinematográfica en la Amazonía brasileña. Los autores presentan, de hecho, los resultados de un proyecto de investigación que indaga cómo un grupo de jóvenes del pueblo sateré-mawé logra apropiarse y utilizar la herramienta cinematográfica como vector de expresión crítica.

Lo sugerente de la experiencia relatada en este trabajo reside en la manera en que sus protagonistas -los jóvenes sateré-mawé- denuncian el 
mantenimiento y la resiliencia de la situación colonial y, a la vez, buscan descolonizar “en imagen” las representaciones tanto negativas como folclóricas que se vehiculan sobre los pueblos indígenas en la producción cinematográfica de masa. El cine se constituye así en una oportunidad para darse a mostrar de una manera distinta, lejos de las tradicionales y -muchas veces- negativas imágenes estereotipadas sobre los “indios”. El artículo evidencia así el rol y la importancia del control ejercido sobre las representaciones respecto del proceso de descolonización en el cual numerosos pueblos indígenas se han comprometido en la región.

No dejemos de mencionar que, en esta "guerra de representaciones”, la realidad urbana ha sido indudablemente la faz más invisibilizada de la contemporaneidad indígena, pese a que los llamados indígenas urbanos constituyen hoy una indiscutible mayoría en muchos países latinoamericanos. Distanciándose de aquella representación muchas veces idealizada que asocia tácitamente lo indígena a lo rural y lo tradicional, Juan Manuel Engelman se enfoca, en su artículo, en una experiencia organizacional indígena al sur del conurbano bonaerense, abordando la ciudad como un escenario de fortalecimiento identitario, más que como un espacio de aculturación “sin indios” como se la suele interpretar. Propone así una reflexión crítica del quehacer antropológico clásico en relación a lo que él identifica como “cuestión étnica urbana”, en un esfuerzo por considerar la ciudad -en tanto lugar estratégico en la geografía del poder colonial- como un espacio de reconfiguración identitaria y recomposición territorial para los grupos indígenas que la practican.

El artículo de Engelman ofrece de esta forma interesantes pistas de reflexión hacia un campo aún baldío en las ciencias sociales latinoamericanas -ni cubierto tampoco por este dossier- referido a los procesos interculturales en contextos urbanos, sea en materia educativa u otros ámbitos. En un contexto en que, como ya lo mencionamos, la mayoría de los indígenas se vinculan hoy directa o indirectamente con el medio urbano, parece imprescindible contar con una experticia que pueda, entre otros, servir como marco de referencia para la elaboración o formulación de políticas públicas adecuadas. La escuela, por cierto, es nuevamente llamada a cumplir un rol fundamental en estos procesos. Pero ya no con el fin de "modernizar" a los indígenas, como suele haber ocurrido al focalizar las políticas de EIB en sectores rurales o “tradicionales”, sino para sensibilizar e interculturalizar a quienes muchas veces poco o nada saben de sus vecinos indígenas con quienes incluso ignoran cohabitar.

A la luz de las enseñanzas de esta sección monográfica, y para no recaer en el ya tradicional escollo de las políticas de la interculturalidad, una particular atención deberá efectivamente ser prestada a la necesidad -jimperiosa!- de considerar y orientar prioritariamente dichas políticas a la población no indígena. La apuesta, en términos descolonizadores, es enorme y puede ser sintetizada en dos puntos principales: 1) desruralizar la representación popular del sujeto indígena, y 2) superar la antinomia supuesta de los vocablos “ciudad” e "indígena”. 
Por otra parte, la consideración de políticas públicas orientadas a la población no indígena habilita una noción ampliada de "interculturalidad", desligándola de la asociación lineal y reduccionista con lo indígena. Muchas preguntas surgen y continuarán surgiendo a la hora de adoptar este enfoque, reafirmando una vez más y, en definitiva, la historicidad y el carácter altamente dinámico de los procesos interculturales en cuestión. En un sistema mundo capitalista moderno / colonial, al decir de Aníbal Quijano ${ }^{1}$, comprender la interculturalización de los currículos como práctica política orientada a la descolonización, significa también ampliar las perspectivas de democratización que nuestras sociedades se adeudan y se merecen.

Este número se enriquece con la interesante reflexión crítica que sobre colonialidad y descolonización nos aporta Josef Estermann, desde la perspectiva de la filosofía intercultural e incluida en la sección Cartografías para el Futuro. En ella propone algunos criterios que posibilitan discernir entre posturas "celebratorias" por un lado y por otra posturas “críticas” y "emancipadoras". Cuestión esta de enorme importancia, ya que el discurso de la "interculturalidad” y “descolonización” sufre, al igual que todo discurso nuevo y rupturista, un proceso de desgaste y cooptación por parte del hegemónico modelo monocultural que apunta a globalizar en la dirección de un imperialismo cultural occidental y de una posmodernidad en clave consumista.

El número se completa con su sección Propuestas y avances de investigación que incluye un total de diez artículos y en su sección Comentarios y reseñas de libros un total de siete trabajos. 


\section{Nota}

${ }^{1}$ Quijano, Aníbal (2000), "Colonialidad del poder, eurocentrismo y América Latina", en Edgardo Lander (compilador), La colonialidad del saber: eurocentrismo y ciencias sociales. Perspectivas latinoamericanas, Consejo Latinoamericano de Ciencias Sociales (CLACSO), Buenos Aires, pp. 201-246. 